\title{
Propranolol Blocks the Extrasynaptic Nicotinic Receptors on the Intramural Cardiac Ganglion Cells
}

\author{
KOZO IKEDA, HIROE INOKUCHI, HIDEHO HIGASHI AND SYOGORO NISHI \\ Department of Physiology, Kurume University School of Medicine, Kurume, 830 Japan
}

Received for publication May 26, 1986

\begin{abstract}
Key words: cardiac ganglion cell - nicotinic receptor - extrasynaptic receptor - acetylcholine $(\mathrm{ACh})$ potential - fast EPSP - atrial contraction
\end{abstract}

Nicotine has long been characterized as having two phases of action on the heart, initially negative and subsequently positive chronotropic and inotropic effects. The nicotine-induced inhibition has been generally assumed to be due to activation of the nicotinic receptors on the cardiac ganglion cells that fires the axons, liberates acetylcholine (ACh) and eventually inhibits atrial contractions (Giotti, 1954;
Leaders and Long, 1962; Chiang and Leaders, 1965; Khan et al. 1965; Long and Gross, 1966; Chiang and Leaders, 1968). Odawara and Nishi (1980) have shown, however, that the nicotine-induced inhibition of the isolated guinea-pig atrium can occur after blockade of the nerve conduction by tetrodotoxin. They reported that the axon terminals of cardiac ganglion cells are endowed with nicotinic recep-
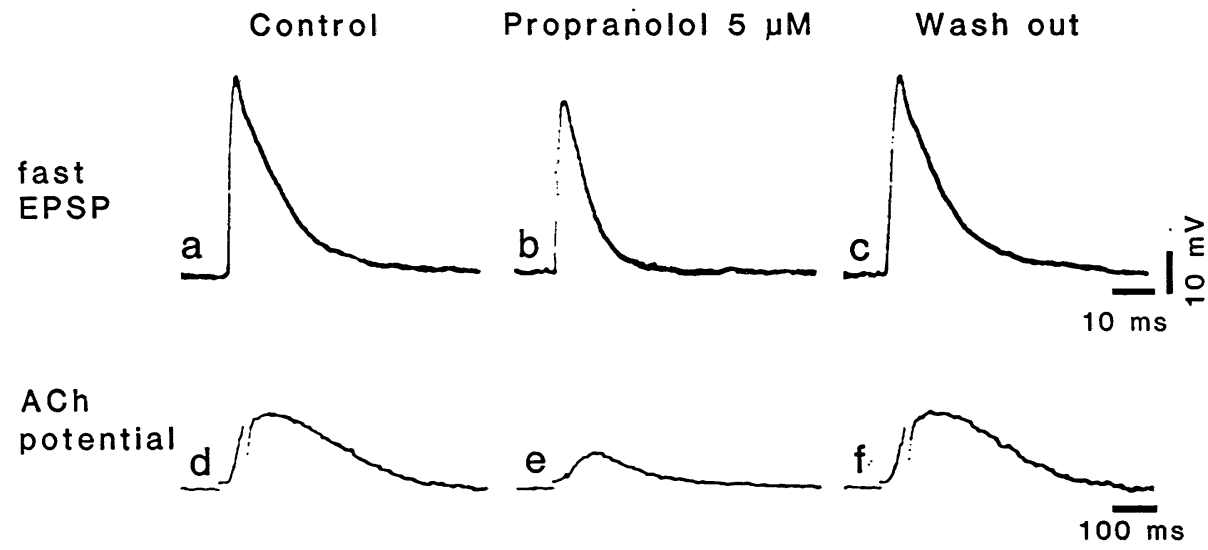

Fig. 1. Alteration by propranolol of the nicotinic responses of intramural ganglion cells isolated from guinea-pig atrium. $a-c$ : Fast EPSPs of a neuron elicted at membrane potential of $-80 \mathrm{mV}$ by single focal stimuli. $d$ - $f$ : Responses (fast ACh potentials) of another neuron at a resting membrane potential of $-52 \mathrm{mV}$ induced by electrophoretic application of $\mathrm{ACh}$ by pulses of $0.1 \mu \mathrm{A}$ with a duration of $30 \mathrm{msec}$. Records were taken intracellularly before $(a$ and $d$ ) and $5 \mathrm{~min}$ after ( $b$ and $e$ ) addition of propranolol $(5 \mu \mathrm{M})$ to the perfusing solution and $15 \mathrm{~min}$ after ( $c$ and $f$ ) washing out propranolol. 
tors, and activation of these receptors by nicotine causes liberation of the endogenous ACh which then inhibits atrial contractions. Imawatari (1982) found that propranolol reversibly blocks the nicotineinduced inhibition of guinea-pig atrium and suggested that propranolol suppresses the nicotinic receptors at the axon terminals.

We have recently investigated the effect of propranolol on the nicotinic responses of the intramural cardiac ganglion cells and reached a conclusion that propranolol selectively inhibits the extrasynaptic nicotinic receptors.

The intramural ganglia were isolated from the guinea-pig atrium and super- fused in vitro at $36 \pm 1{ }^{\circ} \mathrm{C}$. Single ganglia were fixed to the bottom of the perfusing chamber covered with a thin layer of Sylgard (Dow Corning). The fixed ganglion has intact neural connections with the remainder of the intramural plexus. Neurons were directly observed during intracellular recording using Nomarski optics $(500 \times)$. The full methods of fixation, perfusion, intracellular recording, focal stimulation of the ganglion, and $\mathrm{ACh}$ electrophoresis were similar to that described by Nishi and North (1973).

As illustrated in Fig. 1, propranolol (5 $\mu \mathrm{M})$ markedly depressed the fast $\mathrm{ACh}$ potential induced by ionophoresis, while it only slightly depressed the fast EPSP

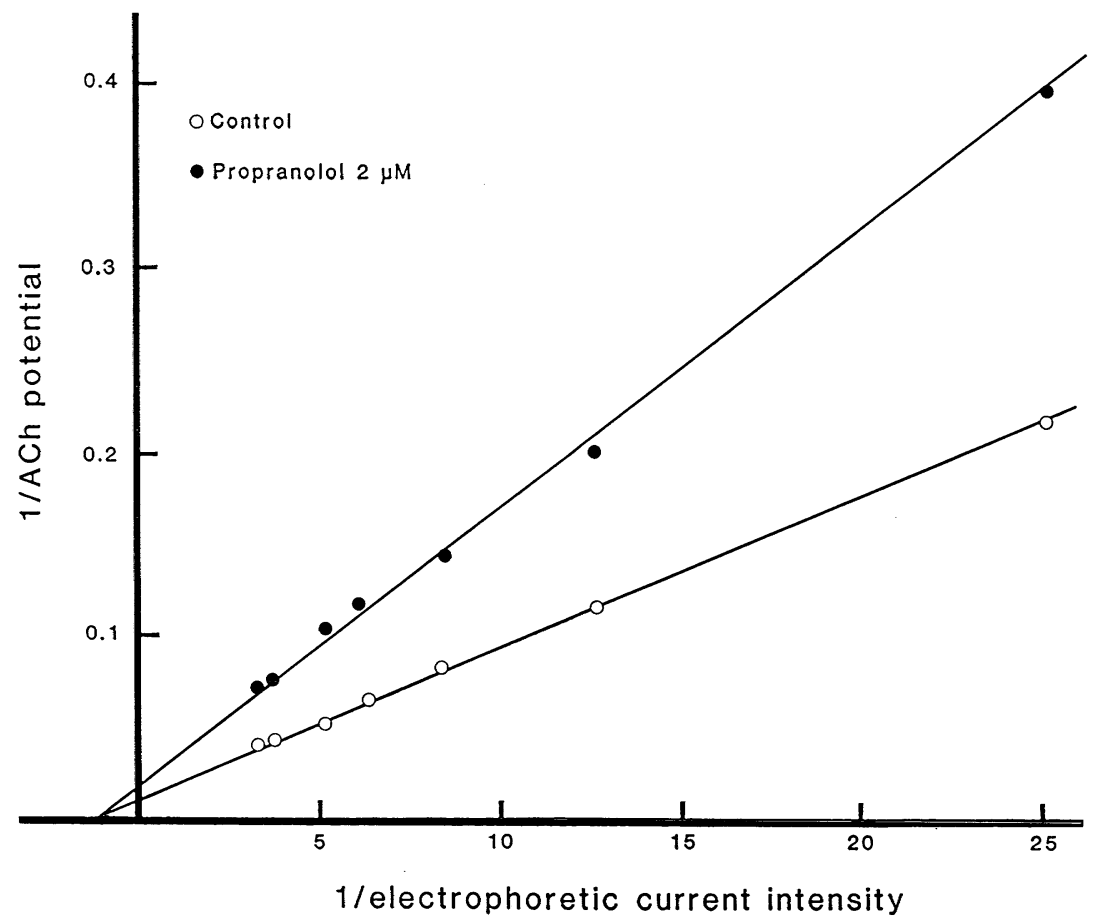

Fig. 2. Dose-response relationship for the fast $\mathrm{ACh}$ potential in the presence and absence of propranolol. Reciprocals of the fast ACh potential (ordinate) and electrophoretic current intensity (abscissa) are plotted. Values were obtained from the same neuron before (open circles) and 5-8 min after (close circles) addition of propranolol $(2 \mu \mathrm{M})$. The resting membrane potential was $-52 \mathrm{mV}$. The amplitude of the fast ACh potential was corrected by Martin's method (1955). 
elicited by focal stimulation. When the fast EPSP was elicited at a hyperpolarized level (e. g., $-80 \mathrm{mV}$ ) of membrane potential, a hump was observed on the falling phase of the EPSP near its peak. Thus, the falling phase had an initial fast decay phase (time constant, 5 to $8 \mathrm{msec}$ ), a hump and a slow decay phase (time constant, approximately $15 \mathrm{msec}$ ). Propranolol (5-10 $\mu \mathrm{M})$ eliminated the hump and the slow decay phase, leaving only the fast phase. It might be anticipated that the hump and the slow decay phase of the fast EPSP are produced by activation of the extrasynaptic receptors by the liberated $\mathrm{ACh}$, and that the short-lasting EPSP remaining in the presence of propranolol is generated by activation of the subsynaptic receptors.

The dose-response relationship for the fast ACh potential during propranolol (2 $\mu \mathrm{M})$ application appeared to be that of non-compettive type (Fig. 2). This suggests that propranolol acts on the allosteric site or the ionic channels associated with the extrasynaptic receptors.

Thus it is most likely that there exist two kinds of nicotinic receptor on cardiac ganglion cells; one with a fast kinetics and hardly sensitive to the blocking action of propranolol and the other with a slow kinetics and highly sensitive to propranolol. It would be reasonable to assume that the nicotinic receptors at the intramural axon terminals are similar, if not identical, to the extrasynaptic nicotinic receptors on the ganglion cell somata. Based on these considerations, abolition by propranolol of the nicotine-induced atrial inhibition would be primarily due to suppression of the nicotine-induced depolarization at the postganglionic axon terminals.
Acknowledgment: This study was supported in part by a Grant-in-Aid for Scientific Research from the Ministry of Education, Science and Culture of Japan.

\section{References}

Chiang, T.S. and Leaders, F.E. (1965). Mechanism for nicotine and DMPP on the isolated rat atria-vagus nerve preparation. J. Pharmacol. Exp. Ther. 149, 225-232.

Chiang, T.S. and Leaders, F.E. (1968). Dissociation between the initial negative and the secondary positive chronotropic and inotropic effects of nicotine in rat atria. Arch. Int. Pharmacodyn. Ther. 172, 347-355.

Giotti, A. (1954). Interaction of nicotine and eserine, ephedrine, atropine, hexamethonium and adrenaline in isolated guinea-pig auricles. Br. J. Pharmacol. 9, 15-23.

IMAẂATARI, R. (1982). Effects of propranolol on the nicotinic acetylcholine receptors. J. Kurume Med. Ass. 45, 1009-1023 (in Japanese).

Khan, M., Mantegazza, P. and Piccinini, F. (1965). Effect of low temperatures on the responses of guinea-pig isolated atria to nicotine and to sympathetic and parasympathetic stimulation. Br. J. Pharmacol. 25, 119-125.

Leaders, F.E. and Long, J. P. (1962). Mechanism of the positive chronotropic response to nicotine. J. Pharmacol. Exp. Ther. 137, $206-212$.

Long, J. P. and Gross, E. G. (1966). Studies on the auricular stimulating action of nicotine. Arch. Int. Pharmacodyn. Ther. 161, 30-37.

Martin, A.R. (1955). A further study of the statistical composition of the end-plate potential. J. Physiol. (Lond.) 130, 114-122.

Nishi, S. and North, R.A. (1973). Intracellular recording from the myenteric plexus of the guinea-pig ileum. J. Physiol. (Lond.) 231, $471-491$

Odawara, K. and Nishi, S. (1980). The nicotinic receptors at the vagal efferent nerve terminals in the atrium. Proc. Internat. Union Physiol. Sci. 14, 618. 